Technological University Dublin ARROW@TU Dublin

\title{
Shifting Perceptions within Online Problem-Based Learning
}

\author{
Roisin Donnelly \\ Technological University Dublin, roisin.donnelly@tudublin.ie \\ Timo Portimojärvi \\ University of Tampere
}

Follow this and additional works at: https://arrow.tudublin.ie/ltcbk

Part of the Educational Methods Commons, and the Higher Education Commons

\section{Recommended Citation}

Donnelly, R., \& Portimojärvi, T. (2008). Shifting Perceptions within Online Problem-based Learning. In P.L. Rogers, G.A. Berg, J. Boettcher, C. Howard, L. Justice \& K. Schenk (Eds.), Encyclopaedia of Distance Learning. 2nd Edition. Hershey, PA: Idea Group Inc. 2008.

This Book Chapter is brought to you for free and open access by the Learning Teaching \& Assessment at ARROW@TU Dublin. It has been accepted for inclusion in Books/Book Chapters by an authorized administrator of ARROW@TU Dublin. For more information, please contact arrow.admin@tudublin.ie, aisling.coyne@tudublin.ie,gerard.connolly@tudublin.ie.

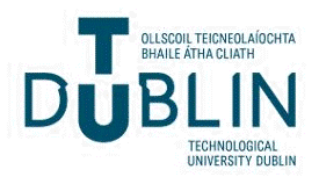




\title{
Shifting Perceptions within Online Problem-Based Learning
}

\author{
Roisin Donnelly* and Timo Portimojärvi
}

Learning and Teaching Centre

Dublin Institute of Technology

14 Upper Mount Street

Dublin 2

Ireland

Tel 0035314027886

Fax 0035316767243

Email: roisin.donnelly@ dit.ie
University of Tampere

Faculty of Education

33014 University of Tampere

Finland

Tel +358 053951174

Fax +358335518850

Email: timo.portimojarvi@uta.fi

\section{INTRODUCTION}

This chapter is aimed at supporting academic staff in universities and colleges who have begun or are considering introducing online problem-based learning (OPBL) for students' learning. OPBL is a promising combination of pedagogical innovations and technological solutions which support and enhance each other. In this chapter we will examine the perceptions present in higher education today, which are connected with the development within the research fields of and problem-based learning. This chapter is based on the recent and extensive emergence of literature on online learning and the success of problem-based learning (PBL). Traditionally, PBL has usually been conducted in a face-to-face setting. Whilst there is a growing researchbase in the area (Donnelly, 2005; Koschmann, 2002; Portimojärvi, 2006; Uden, 2005; Valaitis et al., 2005), it is fair to say that less is still known about the use of PBL in the electronic-based distance-education

In this chapter we delineate the field of OPBL, with a particular emphasis on the interlocking of theory and practice. This will be supported by illustrations of OPBL from the perspectives of both tutors and students on two current modules in higher education. A first section in the chapter will explain the main concepts of PBL and 
explore the implications that recent information and communication technologies (ICTS) have on to it. Then the key differences between the traditional and online environment of PBL will be specified. The chapter will continue with a consideration of suitable technologies and media choices available in a rapidly changing field today. Following on from this, will be a presentation of two case studies on implementing online PBL in both a blended and a distance learning environment. Finally, the chapter will conclude with a summary of the theoretical and empirical aspects of this field and a contemplation of implications for the future.

\section{BACKGROUND: FROM FACE-TO-FACE TO ONLINE PBL}

Problem-based learning (PBL) is a comprehensive approach to learning environments, curriculum, learning, studying and teaching. It is grounded in experiential, collaborative, contextual and constructive theories of learning, and it has clear points of convergence with processes of everyday learning and action. PBL can be used in many formats, such as small-group tutorials, problem-based lectures, largegroup case method discussion, and problem-based laboratories (Kaufman, 1995). However, it is used most commonly in small groups with a facilitator. There have been oft-cited multi purposes to PBL, with these mainly being cognitive effects on students' learning: increased retention and higher comprehension of knowledge (Albanese \& Mitchell, 1993), and in the literature, there are examples that PBL is a valid and valuable means of increasing student learning in any online class where higher-order learning is desirable (Ronteltap \& Eurelings, 2002). Further benefits of online PBL are the development of self-directed learning skills, and the enhancement of students' intrinsic interest in the subject matter, and improved interpersonal skills and teamwork.

The main concept of PBL is that learning starts from problems, which arise from realities of working life or other realities of the field. Problem-based learning involves strategic alignment of the curriculum, not just a change in the method of teaching. It is vital that the culture of the educational institution, the ways of action 
and the tools in use are congruent with each other. Descriptions of learning, collaboration and tutoring do not transform into the practices of action, if practitioners do not have suitable tools or techniques for this. Methods of learning, assessing and working, which emphasise group- and student-centred learning related ways of assessment, are difficult to apply if the set of values and the culture of an institution do not support these (Bielaczyc 2001; Poikela \& Poikela 2005). Beginning in the 1960's with a rather pragmatic origin, PBL has spreaded out in different variations throughout the world, yet, arguably still preserving its foundations (Boud \& Feletti 1997; Uden 2005). The interest in the effects of PBL has produced three meta-analysis (Albanese \& Mitchell, 1993; Dochy et al., 2003; Vernon \& Blake, 1993), which all have similar conclusions on positive effect of PBL on skills but not significant difference on knowledge when compared to traditional curriculum. Continuous theoretical attempts to come to a deep understanding of the area and develop it further have created a need for negotiation in specific aspects. PBL is often seen as group-intensive, experience-based, socio-cultural and context-related or as more traditional, student-centered, and a constructivist form of learning (AlankoTurunen, 2005; Wertch, 2002). Despite the broad acceptance of a general description of PBL and its associated outcomes, Maudsley (1999) and Savin-Baden (2003) point out the enormous variance in the way PBL is conveyed and practiced. Savin-Baden suggests that the differences within the community of problem-based learning is essentially rhetorical rather than a fracture in pedagogy.

\section{MAIN FOCUS: WHAT IS ONLINE-PBL?}

The change in education and working practice and tools over the last ten years has been truly remarkable. The old dichotomy of traditional face-to-face and distance education is becoming obsolete in both arenas as more diverse mixed-mode forms of education and training delivery emerge. In today's so-called where there now exists new technologies and new structures for knowledge construction, new challenges emerge. 
There have been several attempts to define terms for the combination of e-learning and PBL, but an established one is still in development. Definitions such as distributed PBL (Koschmann, 2002) or computer-mediated PBL (Dennis, 2003) are connected with research traditions of computer-supported collaborative learning (CSCL) and computer-mediated communication. Savin-Baden \& Howell-Major (2004) have suggested that the term computer-mediated PBL has been used initially to define any form of PBL that utilizes computers in some way. However, this is seen as problematic since it offers little indication about the ways in which computers are being used, the areas of student interaction, the quality of the learning materials or the extent to which any of these integrate with PBL. In this chapter we use OPBL to describe our combination of these traditions and to describe the ways of using technology and PBL processes together.

The learning groups in PBL can benefit from 'blending' virtual and physical resources, examples of which include combinations of technology-based materials and traditional print materials. The fact that the Internet is a complex repository containing a huge maze of information from a variety of sources, has impacted on the PBL landscape in that it has become a prominent source of information for disciplinary groups. The use of online communication technologies also provide many ways in which distance educators can facilitate flexible tutorial support to groups of students (Fox, 2005).

In addition, a number of researchers have drawn attention to the need for online group work as part of the formation of graduates, given the recognized importance of having the ability to work in groups in the workplace. Working in a dispersed organization requires open communication, mutual trust and shared processes and virtual tools (Vartiainen, et al., 2003).

\section{What is the main difference between online and f2f PBL?}


There are several core differences between how traditional and online PBL is delivered, primarily around the area of flexibility. Engaging learners from different locations in working together could benefit the PBL group through their offering of multiple perspectives to the Problem. Ongoing group work could also be better ensured even if some of its members are temporarily unavailable. A further consideration that is especially important in distance education is that of student motivation. Brown and Voltz (2005) found that distance learning students displayed high levels of motivation and engagement because of the immediate and rich feedback provided by activity. Arguably this needs to be balanced against a need by some learners for a need for face-to-face contact and direct student support mechanisms.

However, it is not all a rosy picture in the online learning environment. Whilst conflict is a normal feature of most groups that meet over a period of time, Macduff (1994) and Palloff and Pratt (1999) argue that the electronic medium produces a greater likelihood for conflict because of absence of non-verbal, facial and body cues and the difficulty of expressing emotion through text.

The level of interaction in distance education, whether it is via PBL or not, is affected by the choice of synchronous or asynchronous delivery. can assist with maintaining levels of motivation in that, if used well, it can focus the energy of group and encourage students to keep up with their peers and continue with study. It can help create a feeling of community and classroom cohesion, and rapid feedback can foster consensus-building in group activities. From the tutor's point of view, it can also help keep students up-to-date with the course.

Situated learning can take place when the technology allows access from home or work, so that the learner may have opportunities to integrate ideas being discussed on the course. Along with providing access to the learning materials, which can take place at any time, asynchronous delivery in an online PBL environ, allows time for reflection. Rather than having to react instantly, it allows the learner to reflect over 
ideas, check references and take time to prepare a reply. Taken further, if the session is recorded and archived then students can go back and review the lesson.

A further key difference between online PBL and face-to-face PBL is the

tutor. It is important to recognise the abundance of research and literature on the role of the tutor within problem-based learning, and the similar wealth of work being produced in recent years on the classification of tutor roles in an e-learning environment. In the recent past, Hughes and Daykin (2002) have suggested that a move to online delivery needs a greater attention to design and development of facilitator skills than has been previously recognised. Multiple methods for online instruction are utilized throughout academe. One method, described as the online learning community, has become preeminent in online instruction. Boettcher and Conrad (1999, p. 88) have defined an online learning community as a community that "consists of learners who support and assist each other, make decisions synergistically, and communicate with peers on a variety of topics beyond those assigned." It is this building of this learning community by the PBL tutor in face-toface PBL tutorials and sustaining it online, that remains both challenging and worthy of further investigation.

As researchers report the various challenges faced by learners in online PBL (Lohman \& Finkelstein, 2000; Orrill, 2000) and online collaborative learning (Zhang \& Harkness, 2002), a skillful tutor may help address some of the issues and challenges in the group learning process. Research suggests, therefore, that learning is largely a social activity, that learning in groups generally improves student learning, and successful group work can improve higher-order thinking and learning. However, ultimately a factor that may influence student learning is the sense of connection - or lack thereof - to the central problem that the students face.

So, in summary, is the use of PBL in the online environment any different from the traditional classroom? There are distinct differences between face-to-face PBL and online PBL with regards to the form of communication (asynchronous vs. 
synchronous), the levels of interaction with the problem with each other and the tutor, and the resulting effects on student motivation.

\section{FUTURE TRENDS: OPBL LEARNING ACTIVITIES}

The basic process of problem-based learning activities is constituted by small group tutorials and a phase of information acquisition between them. The tutorial groups are typically long-running in nature varying in time over a period of weeks or months, depending on module structure and the literature recommends that group size can make a difference and normally comprise of anywhere between 4 to 10 students (Arts, 2002; Samford University, 2003). Groups can be assigned as to provide a mix of students to reflect the geographic mix. It is important for the tutor to also manage what media students will be using: chat rooms, email, discussion forums, and other tele/videoconferencing means.

The activities in the group are guided by a tutor, and the group has varying roles of a discussion leader, a recorder and an observer. The discussion leader works to keep the group on track. He or she is charged with ensuring full participation from all group members, and helps to moderate individuals who may try to dominate the group discussion. The recorder keeps track of unresolved issues, records group strategies, maintains archives of all work sheets and electronic files, and convenes the group outside of class as necessary. The observer gives feedback to the group members and leads the group into an assessive discussion in the end of a tutorial session. In addition, some temporal roles may be used to promote certain aspects like productivity, critical thinking or group dynamics. The groupwork starts from an authentic problem, which can be called also a case, trigger or scenario, depending it's nature. During the first tutorial, the group recognizes and elaborates their individual and shared prior knowledge on the matters under discussion. It is on these grounds that the group formulates a shared learning task and reaches agreement for searching for information. 
This is followed by a knowledge acquisition phase. With online PBL it is possible to combine the information retrieval process with the final discussion phase of the traditional PBL-process: students can discuss their outcomes immediately after they found relevant information and if necessary adjust their problem-solving strategy. In the traditional PBL setting students have to wait for the next group meeting. However, a synchronous face-to-face meeting seems to be important for the final synthesis. It is vital that combining and synthesising the acquired knowledge is built into the process. The outcome is supposed to be a shared, best possible understanding on the matter under discussion.

\section{Consideration of the variety of media (both synchronous and asynchronous)}

Each of the phases of the problem-based learning process have specific, even unique forms of action and communication. In particular, the online learning applications require that these characteristics should be resolved and understood before being utilised within online environments, which in themselves, have certain limitations. The communication among groups varies from very fast, intensive and involving interactive tasks (e.g. brainstorming, debating or role-playing) to cautious and individual modes of information searching. In addition to these, groups often use collaborative ways of creating mutual understanding by using visual or other aids, like whiteboards, mind maps or concept maps which help the group members to create a shared space for exploring the prior knowledge or for creating a shared conceptual synthesis of the group members' shared knowledge (Portimojärvi 2002; Buzan 2001; Novak \& Govin 1984).

Figure 1: The communicative forms of a PBL cycle.

Figure 1 illustrates the process of a PBL cycle and the forms of communication and media for online problem-based learning. These specifications are based on traditional face-to-face tutorial settings. They are coherent and can be understood 
from the perspectives of media synchronicity theory (Dennis \& Valacich 1999), common ground theory (Clark \& Brennan 1991), media richness theory (Daft \& Lengel 1986) and social presence theory (Short, Williams \& Christie 1976). Research on audio- and and

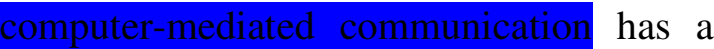
tradition of more than 40 years. Wainfan \& Davis (2005) have extensively reviewed this tradition and tools of mediated group interaction, and they have concluded with reasonably parallel results to our development in combining synchronous and asynchronous communication in different tasks. These matters require more detailed research on communicative activities and technological solutions, which support distributed collaborative tasks. (Portimojärvi, 2006).

\section{Implications for Academic Staff}

There are a number of issues which need to be taken into account by any lecturer wishing to combine these two approaches. Developing tutor's online facilitation capabilities, designing and producing synchronous events to support students, encouraging collaborative interactive participation and finding ways of engaging students who seldom participate in the online PBL group.

OPBL needs to be focused on a group-oriented, knowledge-building discourse and students should work collaboratively in real-time or asynchronously to manage the problem. Although using e-learning in conjunction with PBL has a number of advantages, (such as students having access to wider resources and often innovative problems, new and different forms of dialogue and immediacy in communication and learning), there are also a number of difficulties to be overcome. Students can very easily be overloaded with information. Indeed Salmon (2000) in offering a guide to tutors online, advocates that participants find it easy and enjoyable to share information online, and a great deal of information suddenly becomes available. However, in order to avoid information overload, participants develop personal strategies for dealing with the flurry of messages that occur at this stage. Online tutors at this stage facilitate activities that provide stimulation and provide guidance in 
constructive use of learning materials and effective information sharing. In addition, problem scenarios may be pitched in terms of complexity of rather than of the development of criticality.

Communication problems can also arise both within the group and between the group and the tutor(s); essentially this is because of the difficulties of understanding textbased dialogue rather than live dialogue. PBL is an approach that relies strongly on communication and learning through dialogue, and if the text-based communication (chat or email) is misunderstood or tutor feedback is received as negative when it was trying to be developmental, this can lead to discontentment and disjunction.

In many ways, it could be argued that designing OPBL is no different from other forms of PBL, in that it needs to be designed with sound pedagogical foundations and not as merely providing an innovative approach to learning.

The teacher, and the teacher-educator as an agent of change plays a pivotal role in the teaching-learning process in OPBL. It is necessary to emphasize the role of teachers as pedagogical agents who want to undertake quality online teaching, and it is believed here that sustained professional development opportunities for teachers in facilitating OPBL is key to success.

\section{Case Studies from Ireland and Finland}

Through the presentation of two international case studies from the field of OPBL, this final section in the chapter explores some of the common issues encountered by academic staff and participants. The cases have similarities in both backgrounds and goals. In both cases, the module or course participants are drawn from very diverse fields, and have spent varying lengths of time as lecturers. There is present also a wide range of knowledge and experience about both online learning and PBL, ranging from novice to intermediate or even expert. All participants are self-selecting and choose to come on the course. A specific approach was taken to the design and 
delivery of these modules by using problem-based learning as the dominant pedagogical model. The courses were designed and delivered independently and comparison and co-operation between them started later.

\section{Irish Case Study}

This module uses problem-based learning as a means of delivery of professional development for academic staff in higher education. It is a ten week (10 ECTS study credits) module entitled 'Designing E-Learning' which is delivered using a blend of face-to-face and online problem-based learning. The entire programme is located within a Faculty of Academic Affairs in the Dublin Institute of Technology in the Republic of Ireland. The online delivery component and support of the module is in the Online Learning Environment, WebCT. See Figure 2 for an outline of the features of this module.

The aim of the module 'Designing E-Learning' is to enable the participants (lecturers, librarians and educational technologists), through a blended learning approach to PBL, to become aware of the practicalities of designing, delivering, supporting and evaluating an online module in their own subject disciplines. In the context of this module, the term 'Blended Learning' refers to a merging of classroom and online activities that must be integrated by the tutor in ways that allows them to deliver learning (both content and tasks) as a coherent and effective whole; they may be individual, group based, or a combination of both. Blended PBL has evolved as a delivery and facilitation approach in the module whereby an online environment has been created to complement a series of face-to-face PBL tutorials with a puzzlement that engages the group of learners in inquiry activities consistent with the learning outcomes of the module. Donnelly (2004) has argued that students working collaboratively on an authentic problem benefit from face-to-face interaction as well as being supported online. This can help eradicate communication problems amongst group members. 


\section{Outline of the Collaborative OPBL approach}

From a design perspective, it was decided to strip the module down to reflect the reality of the context in which it was being delivered. These lecturers in third level education in Ireland were not in the position of having to present courses entirely online. A blended approach with appropriate face-to-face encounters was deemed much more relevant for their and their students' needs. Online delivery took the form of using a range of electronic resources and online asynchronous and synchronous discussion, to solve a problem-based learning scenario. There are a small number of face-to-face sessions strategically placed at the start, middle and end of the module to facilitate cohesiveness, good dialogue, quality tutorial input and individualised support.

After participants gained experience with the flow of activities face-to-face in the PBL tutorials and were thinking deeply about the problem, their online collaborative work begins. The group meet online with the asynchronous feature of the Online Learning Environment, WebCT, that is designed to scaffold participants as they organise their group task, then synthesise, post and critique the results of their deliberations. There are a number of key phases to the blended delivery of the module.

Induction Phase: This induction phase is not assessed. It offers the participants an opportunity to start bonding as a collaborative problem-based learning group in a face-to-face setting. It also extends to participants the possibility to access and test the online learning environment and to solve any technical problems which may occur. Participants are required to give information on themselves and their academic interests in a section of the online learning environment, WebCT.

Literature and Research Phase: Participants are expected to familiarize themselves with relevant knowledge necessary for dealing with eLearning, and retrieve additional relevant literature in order to fulfill the requirements of collaborative problem-based learning for the module. 
Exploration Phase: This phase is dedicated to getting familiar with online learning through working in the interdisciplinary group.

Conception Phase: This involves collaborative problem-based learning work on the design and implementation of an area using all that has been learned about online pedagogy and technology.

Evaluation Phase: The participants will be asked to give a written evaluation of their input, that of their peers, the collaborative problem-based learning group process, and the module itself.

\section{Collaborating at a distance}

Real time online events feature in this model through desk top video conferencing to University of Tampere. The Synchronous Chatroom feature of WebCT is used for problem-solving areas of the curriculum so that the tutor can help students on a oneto-one, or one-to-small group basis. Participants interact with each other through posting email and Discussion Board questions. A video conference link to a guest tutor in the University of Tampere in Finland occurs at the half-way point in the module. Janes (2000) as far back as 1997 has reported the benefits of linking with international guest tutors in an online environment. The strength is the online collaborative discussions, presentations between participants and the interaction between online tutors, participants and international guest tutors.

The purpose of an asynchronous link was to rejuvenate the group work in its later stages by introducing two guest tutors from the University of Queensland. Through such expansion of physical classroom boundaries, an MP3 audio adds live interaction to asynchronous distance learning. Such guest "lecturers" can be invited in to join the conference, so students can interact directly with experts in their fields (Cotlar \& Shimabukuro, 1995).

\section{Finnish Case Study}


During 2004-2006, the Eduta Institute in the university of Tampere organized and coordinated a project entitled "Information Technology and Problem-Based Learning (PBL-IT)". The program consists of 25 ECTS study credits and it was partly financed by the State Provincial Office of Southern Finland and EU Structural Funds. The participants of PBL-IT studies were mainly lecturers from Finnish universities of applied science.

The course had three modules: (1) Problem-Based Learning, (2) Technology and mediated cultures of action, and (3) Groups and tutoring in online environments. These modules created a continuum without clear boundaries. All themes were interwoven together and were discussed in parallel. The subject of the studies was identical with the implementation of the course. All subjects that were studied theoretically were first applied in practice. Some of the learning subjects that arose in the tutorials were repeated and delved deeper as an iterative process. The main learning task for all students was to meet the challenge of combining problem-based learning and online learning with suitable technologies. From this viewpoint, the progress of the course formed a progressive continuum.

The course started with traditional face-to-face tutorials and other activities during the in-service training days. Between them, during the phase of information acquisition, the groups used online learning environments (OLE) such as WebCT or Moodle as an asynchronous tool for discussion and sharing information. This blended course could be called computer-supported traditional PBL. Different technologies were experimented with on the course. Wikis and blogs have just risen to prominence during the course, and in particular, wiki seems to be a totally new type of tool for shared collaboration. After the main procedures of PBL had been internalized, new technologies were presented. During in-service training days, the students simulated totally distributed tutorial settings by using synchronous tools like chat and whiteboard, which were features of e.g. WebCT and CmapTools, which is originally a concept mapping software. It enables synchronous collaboration and can be also 
used for tasks like brainstorming and modelling. These tools allowed text-based communication, and the next natural add-on that was required was voice.

It was obvious that synchronous online meetings had some added value, and working with sound and image seemed challenging. Different tools and software for audio conferences were tested with subgroups or by the students. For instance Skype and TeamSpeak were held potential as types of software, which could be easily combined with shared visual tools such as whiteboards or shared documents. These technological solutions made it possible to have tutorial meetings online. Coordination between different software became an issue. Using two types of software simultaneously during the tutorials, and utilizing another asynchronous software or OLE between the tutorials certainly became a technological challenge to overcome.

The next phase of this development involved improved implementation of personal conferencing. There is a plethora of new software on the market now for this purpose. Mentioned earlier is Skype, which is the best known example of such software; it enables point-to-point or multipoint audio and videoconferencing. For more sophisticated use, there are client-server software such as Breeze or Marratech, which enable real group meetings with advanced tools for collaboration. Marratech was used for personal desktop conferencing on this course, and with it, the tutorial meetings became fairly similar to face-to-face meetings, where everyone could hear and see each other, present materials and work collaboratively on the shared whiteboard. This same software was used also for distance lectures and involvement of national and international guest experts. Combined with the use of the asynchronous Moodle environment, this formed the ensemble of technology that formed the basis of the course.

Following all this technological development and exploration of possible software solutions, we argue that the optimal way of online PBL is a blended solution. Face-toface meetings, desktop conferencing tutorials, distance lectures, asynchronous 
discussion and digital learning materials create an entity. It could be illustrated as a puzzle where each part completes the others.

\section{CONCLUSION: EXPERIENCES, VISIONS}

To conclude, we offer our shared experiences and visions for the future of online problem-based learning in higher education. Problem-Based Learning is a challenging form of pedagogy. Different views and implementations stress different aspects. As illustrated in these two international case studies, even within courses, these aspects may vary.

PBL offers online learning a structure and pedagogical grounding and a motivating and effective way of learning. Over time, we anticipate that our understanding of OPBL and its outcomes will mature and measures of effectiveness will continue to develop and improve.

Technology offers PBL more flexible environments, limited on some aspects but enriched on others. The workload that active participation in online problem-based learning places on students should not be underestimated when the decision is being made to pursue this style of education.

The advanced combinations of problem-based learning and online learning provide effective tools for virtual teams and virtual communities of practice. However, the development of higher levels of skills in the use of online communications is an important consideration in the design of OPBL.

\section{REFERENCES}

Alanko-Turunen, M. (2005). Negotiating interdiscursivity in a problem-based learning tutorial site. Tampere: University of Tampere. Academic dissertation.

Albanese, M., \& Mitchell, S. (1993). Problem-based learning: A review of the literature on its outcomes and implementation issues. Academic Medicine, 68(1), 5281. 
Arts, J., Gijselaers W., \& Segers, M. (2002). Cognitive effects of an authentic computer-supported, problem-based learning environment. Instructional Science, 30, 465-495.

Bielaczyc, K. (2001). Designing social infrastructure: the challenge of building computer-supported learning communities. In P. Dillenbourg, A. Eurelings, \& K. Hakkarainen (Eds.), European perspectives on computer-supported collaborative learning. Proceedings of the First European Conference on Computer-Supported

Boettcher, J.V., \& Conrad, R.M. (1999). Faculty guide for moving teaching and learning to the web. Mission Viejo, CA: League for Innovation in the Community College.

Buzan, T. (2001). The mind map book. London: BBC.

Boud, D., \& Feletti, G. (1997). Changing problem-based learning: Introduction to the Second Edition. In D. Boud \& G. Feletti (Eds.), The Challenge of Problem-Based Learning. London: Kogan Page.

Brown, A., \& Voltz, B. (2005). Elements of effective e-learning design. International Review of Research in Open and Distance Learning, (March 2005).

Clark, H., \& Brennan, S. E. (1991). Grounding in communication. In L. B. Resnick, J. Levine \& S. D. Teasley (Eds.), Perspectives on socially shared cognition. New York: APA.

Daft, R., \& Lengel, R. (1986). Organizational information requirements, media richness and structural design. Management Science, 32(5), 554-571.

Dennis, A.R., \& Valacich, J.S. (1999). Rethinking media richness: Towards a theory of media synchronicity. Proceedings of the 32nd Hawaii International Conference on System Sciences.

Dennis, J.K. (2003). Problem-Based learning in online vs. face-to-face environments. Education for Health,16,(2), 198-209.

Dochy, F., Segers, M., Van den Bossche, P., \& Gijbels, D. (2003). Effects of problem-based learning: A meta-analysis. Learning \& Instruction, 13(5), 533-568.

Donnelly, R. (2004). The effectiveness of teaching 'Online Learning' in a problembased learning classroom environment. In M. Savin-Baden and K. Wilkie (Eds.), Challenging Research into Problem-based learning. Buckingham: Open University Press. 
Donnelly, R. (2005). Using technology to support project and problem-based learning. In T. Barrett, I. Mac Labhrainn, H. Fallon (Eds.), Handbook of Enquiry \& Problem Based Learning. Galway: CELT.

Fox, S. (2005). Reflections of the benefits of the use of the new learning technologies in higher distance education through the prism of a case study. Paper Presented at the $11^{\text {th }}$ Cambridge International Conference on Open and Distance Learning. Sept 05.

Hughes, M., \& Daykin, N. (2002) Towards constructivism: investigating students' perceptions and learning as a result of using an online environment, Innovations in Education and Teaching International, 39(3), 217-224.

Koschmann, T. (2002). Introduction to special issue on studying collaboration in distributed PBL environments. Distance Education, 23(1).

Lohman, M., \& Finkelstein, M. (2000). Designing groups in problem-based learning to promote problem-solving skills and self-directedness. Instructional Science, 28(4), 291-307. Netherlands: Kluwer Academic Publishers.

MacDuff, I. (1994). Flames on the wires: mediating from an electronic cottage. Negotiation Journal, 10 (1), 5-15.

Maudsley, G. (1999). Do we all mean the same thing by problem-based learning? A Review of the Concepts and a Formulation of the Ground Rules. Academic Medicine, 74(2), 178-184.

Novak, J.D., \& Govin, D.B. (1984). Learning how to learn. New York: Cambridge University Press.

Orrill, C.H. (2000). Designing a PBL experience for online delivery in a six-week course. Paper presented at the Annual Meeting of the American Educational Research Association. New Orleans, LA.

Palloff, R., \& Pratt, K. (1999). Building learning communities in cyberspace: effective strategies for the online classroom. San Francisco: Jossey-Bass.

Poikela, E., \& Poikela, S. (2005). The strategic points of problem-based learning. Organizing curricula and assessment. In E. Poikela \& S. Poikela (Eds.), PBL in Context. Bridging Work and Education. Tampere: Tampere University Press.

Portimojärvi, T. (2002).The limits and possibilities of virtual environments in learning. In E. Poikela (Ed.), Ongelmaperustainen pedagogiikka. Teoriaa ja käytäntöä. Tampere: Tampere University Press.

Portimojärvi, T. (2006). The alternation of synchronous and asynchronous communication in online problem-based learning. In Verkkovirityksiä - 
ongelmaperustainen oppiminen ja projektioppiminen verkossa. Joensuu: Northern Carelia Polytechnic. In press.

Ronteltap, F., \& Eurelings, A. (2002). Activity and interaction of students in an electronic learning environment for problem-Based learning. Distance Education, 23(1).

Salmon, G. (2000). E-Moderating. The key to teaching and learning online. London: Kogan Page.

Samford University (2003). Problem-based learning.

http://www.samford.edu/pbl/process_probdesign.html. (Last accessed $5^{\text {th }}$ April 2006).

Savin-Baden, M. (2003). Facilitating Problem-Based Learning. Illuminating Perspectives. Buckingham, England: The Society for Research into Higher Education \& Open University Press.

Saven-Baden, M., \& Howell-Major, C. (2004). Foundations of Problem-based Learning. Berkshire: Open University Press.

Short, J., Williams, E., \& Christie, B. (1976). Communication Modes and Task Performance. In R. M. Baecker (Ed.), Readings in Groupware and Computer Supported Cooperative Work: Assisting Human-Human Collaboration. 169-176. Mountain View, CA: Morgan-Kaufmann Publishers.

Uden, L. (2005). Technology and Problem-Based Learning. Hershey, PA: Information Science Publishing.

Valaitis, R.K., Sword, W.A., Jones, B., \& Hodges, A. (2005). Problem-Based Learning Online: Perceptions of Health Science Students. Advances in Health Sciences Education, 10, 231-252.

Vernon, D., \& Blake, R. (1993). Does problem-based learning work? A meta-analysis of evaluative research. Academic Medicine, 68, 550-563.

Wainfan, L., \& Davis, P. K. (2005). Challenges in virtual collaboration. Videoconferencing, audioconferencing and computer-mediated communication. Santa Monica, CA: Rand Corporation.

Zhang, K., \& Harkness, W.L. (2002). Groups going online in a large class: Critical reflections. Journal of Interactive Instructional Development, 14(3), 14-18. 


\section{KEY TERMS}

Asynchronous communication: This form of electronic communication does not rely on participants being available at the same time in order to converse. Examples of this twoway communication include eMail, and electronic forums (often called conferences, bulletin boards or discussion forums). Participants are able to respond at their own pace and in their own time.

Collaborative learning: An instruction method in which students work in groups toward a common academic goal.

Computer-mediated communication: The core activity of computer-mediated communication involves individual members of a learning community composing text at a computer that is networked: the text may be read and responded to by others in that community, wherever they are and whenever they choose. Contributions are held on an archived network and the effect is a kind of unfolding, written conversation.

Distance learning: A type of education, typically college-level, where students work on their own at home or at the office and communicate with faculty and other students via email, electronic forums, video conferencing, chat rooms, bulletin boards, instant messaging and other forms of computer-based communication.

Information and communication technologies (ICTs): This is an umbrella term that includes any communication device or application, encompassing: radio, television, cellular phones, computer and network hardware and software, satellite systems and so on, as well as the various services and applications associated with them, such as videoconferencing and distance learning. ICTs are often spoken of in a particular context, such as ICTs in education, health care, or libraries. The term is somewhat more common in Europe than the U.S.

Synchronous communication: Two-way communication that requires participants to communicate at the same time, though they may be separated geographically. Webcams, 
video-conferencing and instant messaging are examples. In PBL Online times may be set for synchronous discussion between virtual group members and the tutor.

Online learning community: An online learning community is a common place on the internet that addresses the learning needs of its members through proactive partnerships. Through social networkingand technology, people work as a community to achieve a learning objective as defined by the educator. An online community is also where people can talk to each other via microphones and other related sources via the internet

Video Conferencing: A videoconference (also known as a videoteleconference) is a set of interactive telecommunication technologies which allow two or more locations to interact via two-way video and audio transmissions simultaneously. It has also been called visual collaboration and is a type of groupware. The core technology used in a videoteleconference system is digital compression of audio and video streams in real time. 